\title{
Comparative self-assembly studies and self-sorting of two structurally isomeric naphthalene-diimide (NDI)-gelators
}

\author{
ANINDITA DAS, MIJANUR RAHAMAN MOLLA and SUHRIT GHOSH* \\ Polymer Science Unit, Indian Association for the Cultivation of Science, Kolkata, 700032, India \\ e-mail: psusg2@iacs.res.in
}

\begin{abstract}
We have reported here a comparative self-assembly and gelation studies of two isomeric bis-amide functionalized NDI-derivatives. In one case (NDI-1) the two amide groups were placed symmetrically on either side of the chromophore while for the other system (NDI-2) they were located on same side. In non-polar solvent both isomers formed self-assembled structures by synergistic effect of $\pi$-stacking and hydrogen-bonding. The propensity for self-assembly of NDI-1 was greater due to symmetrical placement of two amide groups on either arms of this chromophore which allowed $\pi$-stacking in tandem with hydrogen-bonding, while NDI-2 formed thermally more stable self-assembled fibres possibly due to location of two amide groups in close proximity along single arm of this chromophore. The structural difference in these two isomers lead to distinctly different morphology of their respective self-assembled structures which was further reflected on their gelation properties. Morphology of the self-assembled array of NDI-1 showed organized and regular entangled bundles of nanorods which imparted better gelation ability to this chromophore while the self-assembled fibres of NDI-2 showed less ordered and irregular fibres. We also probed self- assembly of these two chromophores in their mixture which revealed orthogonal assembly of the individual chromophores and no molecular mixing was noticed.
\end{abstract}

Keywords. Self-assembly; hydrogen-bonding; $\pi$-stacking; organogels; self-sorting.

\section{Introduction}

Supramolecular-assembly ${ }^{1}$ and gelation ${ }^{2}$ of various functional $\pi$-conjugated chromophores have been extensively studied in the recent past due to the possibility of tuning their photophysical properties as well as transport properties in the self-assembled state. The motivation stems from the desire to explore such self-assembled materials for various organic electronic device applications such as solar cells, light harvesting systems, organic thinfilm transistors, organic light-emitting diodes and so forth. ${ }^{3}$ In the recent past, some extensively studied organogelators based on various functional $\pi$-systems include porphyrins, ${ }^{4}$ oligothiophenes, ${ }^{5}$ phthalocyanines, ${ }^{6}$ oligophenylenevinylenes, ${ }^{7}$ tetrathiafulvalenes, ${ }^{8}$ perylenebisimide, ${ }^{9}$ naphthalenediimide, ${ }^{10}$ merocyanine, ${ }^{11}$ etc. Some of these semiconductor-based gelators $^{3,5 a-c, f, g, 8 a, 9 e, f}$ have already shown encouraging prospect for them to be investigated further as future materials in organic electronics. In the recent past we have been interested in understanding such structural-property relationship in self-assembly and

\footnotetext{
${ }^{*}$ For correspondence
}

gelation of various 1,4,5,8-Naphthalenediimide (NDI) derivatives. ${ }^{12}$ It is noteworthy that NDIs have been established as one of the best $n$-type semiconducting material ${ }^{13}$ due to high electron mobilities, solution processability, good light absorption characteristics and air-stability. Furthermore, they have been extensively used in constructing various supramolecular arrays like foldamers, ${ }^{14}$ rotaxanes, ${ }^{15}$ catenenes, ${ }^{16}$ ion channels, ${ }^{17}$ bolaamphiphiles, ${ }^{18}$ organogels ${ }^{10}$ and in various supramolecular photosystems. ${ }^{19}$ Thus we envisage understanding structural effect on self-assembly of this very important class of chromophore will be highly relevant in their potential utility in various optoelectronic device applications. In this context, chromophore based building blocks provide an opportunity to relate between the nature of inter-chromophoric interaction and gelation because in such cases one can independently study the self-assembly at dilute solutions by spectroscopic methods and can correlate those observations with gelation phenomenon. Recently we have reported one such study ${ }^{12}$ wherein we probed the self-assembly of a series of bis-amide functionalized NDI-derivatives as a function of the spacer-length between the chromophore and the amide groups. Here we report the comparative self-assembly and gelation 


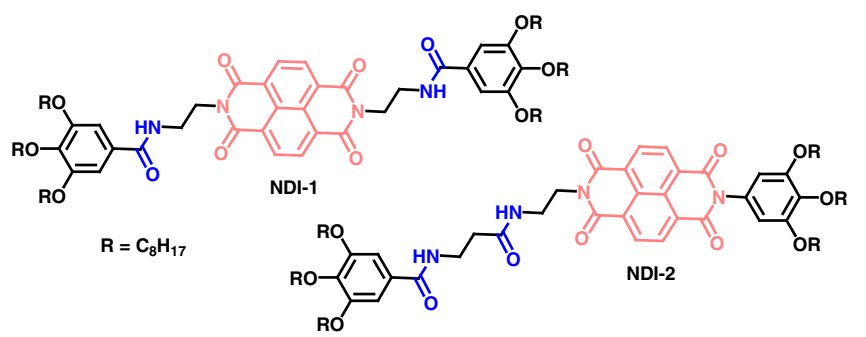

Scheme 1. Structures of two NDI-chromophores.

studies among NDI-1 ${ }^{20}$ and NDI-2 ${ }^{21}$ (scheme 1). Both contains a naphthalenediimide chromophore functionalized with two amide groups capable of hydrogenbonding and peripheral hydrophobic trialkoxybenzamide units to impart solubility to the molecules in non-polar solvents in which hydrogen-bonding is most influential.

Contrasting structural difference between these two molecules were for NDI-1, the two amide groups were symmetrically placed on both arms while for NDI-2 they were appended asymmetrically along one side of the chromophore. Our motivation to study self-assembly of NDI-2 is that unlike most of the chromophoric-gelators studied till date this is an unsymmetrical building block which is expected to impart directionality to the resulting $\pi$-stacked assembly and thus provides opportunity to anchor additional functionality on the gel-fibres with desired spatial location. In this report, we reveal systematic self-assembly and gelation studies of NDI-1 and NDI-2 in various solvents and also their self-sorting property in equimolar mixture.

\section{Experimental}

\subsection{Materials and methods}

Solvents used for the physical experiments were of spectroscopic grades. For UV-vis studies, spectra were recorded in a Perkin Elmer Lambda 25 spectrometer. ${ }^{1} \mathrm{H}$ NMR spectra were recorded in a Bruker DPX$300 \mathrm{MHz}$ NMR spectrometer and calibrated against TMS. Transmission Electron Microscopy (TEM) was performed in JEOL-2010EX machine operating at an accelerating voltage of $200 \mathrm{kV}$. Fluorescence emission spectra were recorded in a FluoroMax-3 spectrophotometer from Horiba Jobin Yvon. Rheological experiments were done in Advanced Rheometer AR 2000 (TA Instruments, USA).

\subsection{Synthesis}

Synthesis of NDI-1 ${ }^{20}$ and NDI-2 ${ }^{21}$ have been described by us elsewhere.

\subsection{Physical studies}

2.3a UV-visible studies: For the solvent variable experiment, stock solution of NDI-1 and NDI-2 were made in $\mathrm{CHCl}_{3}$ at $2.0 \mathrm{mM}$ concentration. $0.1 \mathrm{~mL}$ stock was diluted with proper amount of $\mathrm{MCH}$ to adjust the desired solvent composition and concentration $(0.1 \mathrm{mM})$. The solutions were allowed to equilibrate at room temperature for $1 \mathrm{~h}$ before spectral measurements. The experiment was done in $1 \mathrm{~cm}$ path-length cuvette.

For $\mathrm{MeOH}$ addition experiment, solution $(2 \mathrm{~mL})$ of a particular chromophore in $95: 5 \mathrm{MCH} / \mathrm{CHCl}_{3}(0.1 \mathrm{mM})$ was taken in a cuvette and added with measured amount of $\mathrm{MeOH}$ in multiple steps. UV/Vis spectra were recorded as a function of increasing amount of $\mathrm{MeOH}$.

For temperature variable experiments, solution $(2 \mathrm{~mL})$ of a particular chromophore $(0.1 \mathrm{mM})$ in $95: 5 \mathrm{MCH} /$ $\mathrm{CHCl}_{3}$ was taken in the cuvette and the sample was heated from $25^{\circ} \mathrm{C}$ to higher values with an external temperature controller and spectral measurements were carried out at different temperature. Each time the desired temperature was reached, 10 min equilibrium time was provided before spectral measurement.

For self-sorting experiment, $50 \mu \mathrm{L}$ each of NDI-1 and NDI-2 in $\mathrm{CHCl}_{3}(0.2 \mathrm{mM})$ were mixed together in a vial and diluted with $\mathrm{MCH}(1.9 \mathrm{~mL})$ to adjust the final concentration to $0.1 \mathrm{mM}$.

2.3b Fluorescence studies: For the solvent variable fluorescence experiment, stock solution of NDI-1 and NDI-2 were made in $\mathrm{CHCl}_{3}$ at $2.0 \mathrm{mM}$ concentration. $0.1 \mathrm{~mL}$ stock was diluted with $1.9 \mathrm{~mL} \mathrm{MCH}$ to adjust the final solvent composition $\left(95: 5 \mathrm{MCH} / \mathrm{CHCl}_{3}\right)$ and concentration $(0.1 \mathrm{mM})$.

2.3c Gelation tests: Stock solution of NDI-1 and NDI-2 were made in a good solvent like $\mathrm{CHCl}_{3}$ at a fixed concentration. Measured volume of the stock was taken in a screw capped sample vial and the solvent was evaporated by heating which generated thin-film. To this, known volume of non-polar solvent was added and the mixture was heated with the closed cap, until all the solid dissolved completely and was allowed to cool to room temperature. The formation of the gel was tested by the 'stable-to-inversion of a vial' method. ${ }^{2 c}$ 
Spontaneous gelation could be observed in all cases within 5 min.

For determining the critical gelation concentration (CGC) of a particular sample, the gel was made at relatively higher concentration and gradually diluted with measured amount of the same solvent. Each time after adding the solvent, the sample was heated to get the homogeneous solution and allowed to cool to RT before the gelation was tested. Beyond certain concentration, gelation was not observed even after waiting for few hours and that concentration is reported as the critical gelation concentration.

$T_{\text {gel }}$ was measured by the dropping ball method in which a small glass ball was gently placed on the gel (volume $0.5 \mathrm{~mL}, 5 \mathrm{mM}$ ) in a closed vial which was then immersed in a water bath to allow uniform heating. The temperature of the water-bath was slowly increased by an external temperature-controller. The temperature at which the ball touched the bottom of the vial was noted as the $T_{\text {gel }}$.

2.3d Rheological studies: The rheology experiments were carried out with cone and plate measuring system. For both NDI-1 and NDI-2, $0.7 \mathrm{wt} \%$ gels were made in $\mathrm{MCH}$ and left for $1 \mathrm{~h}$ at RT temperature before taking the measurements. The distance between the cone and the plate was adjusted to remove any air gap between them. The gel was transferred on the plate and stress sweep experiment was carried out by imputing stress on the gel from $0.1 \mathrm{~Pa}-1000 \mathrm{~Pa}$ at a constant temperature of $25^{\circ} \mathrm{C}$. The storage modulus $\left(\mathrm{G}^{\prime}\right)$ and loss modulus $\left(\mathrm{G}^{\prime \prime}\right)$ were plotted as a function of applied stress. The stress at which they crossed each-other was taken as the yield-stress.

2.3e TEM Measurements: $0.2 \mathrm{mM}$ solutions of NDI-1/NDI-2 was made in $95: 5 \mathrm{MCH} / \mathrm{CHCl}_{3}$ and drop casted on copper grid. The sample was left open to the atmosphere for $24 \mathrm{~h}$ (to allow the solvent to evaporate) before taking the images.

2.3f ${ }^{1} H$ NMR spectroscopy: Individual gels and the mixture NDI-1 + NDI-2 (1:1) were made in TCE at $2.5 \mathrm{mM}$ and $5.0 \mathrm{mM}$ concentration respectively. Ten percent $\mathrm{C}_{6} \mathrm{D}_{6}$ in TCE was added to lock the signals. For the temperature variable experiment, sample solutions were heated from $25^{\circ} \mathrm{C}$ to higher temperature with an external temperature controller and the spectral measurements were carried out at different temperatures. On reaching the desired temperature, $10 \mathrm{~min}$ equilibrium time was provided before each measurement. The NMR experiment was performed in $300 \mathrm{MHz}$ spectrometer.

\section{Results and discussions}

\subsection{Self-assembly studies in solution by optical spectroscopy}

Firstly, we probed the self-assembly of the two chromophores by solvent-dependent UV-visible studies using $\mathrm{CHCl}_{3}$ and $\mathrm{MCH}$ solvent composition. Both NDI-1 and NDI-2 were dissolved in a 'good' solvent like $\mathrm{CHCl}_{3}$ in which they remained as monomers. $\mathrm{MCH}$ being a non-polar solvent can induce self-assembly by facilitating both $\pi$-stacking and hydrogen-bonding. Therefore the onset of self-assembly was monitored by varying the solvent composition from $\mathrm{CHCl}_{3}$ to 95:5 $\mathrm{MCH} / \mathrm{CHCl}_{3}$ at $0.1 \mathrm{mM}$ chromophore concentration. In $\mathrm{CHCl}_{3}$ the spectral features of both NDI-1 and NDI-2 looked identical with well-resolved absorption bands within $300-400 \mathrm{~nm}$ due to $\pi-\pi^{*}$ transition along the long axis of the NDI monomer (figure 1). Going from $\mathrm{CHCl}_{3}$ to $\mathrm{MCH}$, a strong hypochromic shift with concomitant bathochromic shift of $3 \mathrm{~nm}$ and $10 \mathrm{~nm}$ was observed for NDI-1 and NDI-2, respectively, suggesting offset $\pi$-stacking. ${ }^{22}$

However for NDI-1, there was a gradual fall in the spectral intensity with increasing MCH content. While for NDI-2, very small change in spectral intensity was noticed till $85 \% \mathrm{MCH}$. Further increasing the $\mathrm{MCH}$ content caused drastic change in both spectral pattern and intensity. Unlike NDI-1, for which the characteristic peaks in the aggregated $(95 \% \mathrm{MCH})$ state could be observed clearly, the aggregated spectrum for NDI-2 appeared broad and featureless. Propensity for selfassembly of the two isomers was estimated by calculating the mole fraction of the aggregates as a function of solvent composition from their respective $\mathrm{MCH}$ titration plot using equation $1 .^{23}$

$A_{\text {agg }}$ and $A_{\text {mon }}$ are the absorbance at $382 \mathrm{~nm}$ for the fully aggregated $\left(95: 5 \mathrm{MCH} / \mathrm{CHCl}_{3}\right)$ and monomeric $\left(\mathrm{CHCl}_{3}\right)$ form, respectively. $A_{\text {mix }}$ is the absorbance at $382 \mathrm{~nm}$ at a given solvent mixture.

$$
\alpha_{\mathrm{agg}} \approx \frac{A_{\mathrm{mix}}-A_{\mathrm{mon}}}{A_{\mathrm{agg}}-A_{\mathrm{mon}}} .
$$

In figure 1c, the $\alpha_{\text {agg }}$ values are plotted as a function of solvent composition for both NDI-1 and NDI-2. From such plots, $\alpha_{50}$ (solvent composition at which $\alpha_{\text {agg }}=$ 0.5 ) were estimated to be $78 \%$ and $86 \% \mathrm{MCH} / \mathrm{CHCl}_{3}$ for NDI-1 and NDI-2, respectively, suggesting onset 

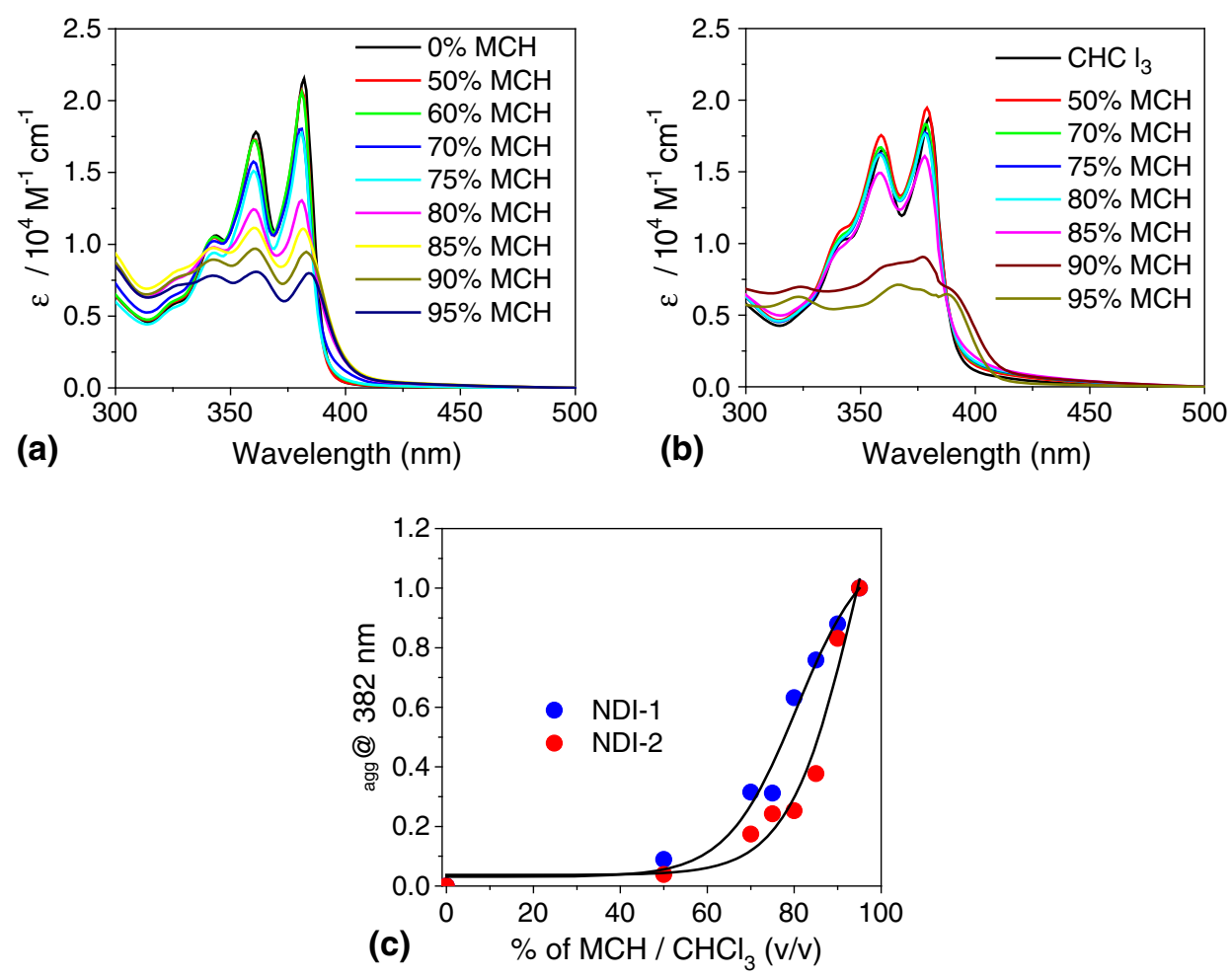

Figure 1. Solvent-dependent absorption spectra of (a) NDI-1 and (b) NDI-2. Concentration $=0.1 \mathrm{mM}$, temperature $=25^{\circ} \mathrm{C}$. (c) Plot of $\alpha_{\text {agg }}$ as a function of solvent composition for NDI-1 and NDI-2.

of aggregation at much lower MCH content for NDI-1 which is also evident from figure $1 \mathrm{a}, \mathrm{b}$.

Self-assembly was further probed by solventdependent emission spectroscopy. The absorption and emission spectra of the two chromophores in their aggregated $\left(95: 5 \mathrm{MCH} / \mathrm{CHCl}_{3}\right)$ and monomeric $\left(\mathrm{CHCl}_{3}\right)$ form are compared in figure 2 .

Going from $\mathrm{CHCl}_{3}$ to $\mathrm{MCH}$, significant increase in the emission intensity (even though absorption decreases) was observed contrary to commonly observed fluorescence quenching for $\pi$-stacking. ${ }^{24}$ When compared the aggregation induced emission enhancement of NDI-1 and NDI-2, it become clear that extent of increase is more for NDI-1 compared to NDI-2. This can be correlated to greater self-assembly propensity for NDI-1 as also observed by solvent-dependent UV-vis studies (figure 1c). Such aggregation-induced increase in emission intensity has been observed for various other chromophores ${ }^{7 b}$ and can be attributed to restriction of conformation flexibility of the chromophores in self-assembled state. Moreover, the emission spectra exhibits almost mirror image relationship with the absorption spectra with very small stoke shift $(8 \mathrm{~nm}$ and $4 \mathrm{~nm}$ for NDI-1 and NDI-2, respectively) and even in the aggregated state one can clearly identify the vibronic features in the emission spectra. ${ }^{25}$ Such spectral features in addition to aggregationinduced enhanced emission have been attributed to $\mathrm{J}$ type assembly for NDI as well as perylene dye in the literature. ${ }^{26}$

To compare the thermal stabilities, we carried out variable-temperature UV-visible absorption experiment of NDI-1 and NDI-2 in their aggregated form in 95:5 MCH/CHCl 3 . From figure 3 it is observed that for NDI-1 with increasing temperature there was no major spectral change till $45^{\circ} \mathrm{C}$. At $65^{\circ} \mathrm{C}$ there was a significant hyperchromic shift with a small blue shift suggesting reversible disassembly. However, even at this stage, the spectral intensity did not match with the monomeric spectrum in $\mathrm{CHCl}_{3}$ suggesting incomplete melting. Note that we could not increase the temperature beyond $65^{\circ} \mathrm{C}$ because of the presence of $\mathrm{CHCl}_{3}$ in the solution. Surprisingly, for NDI-2 very negligible change in the spectral pattern was observed even at $65^{\circ} \mathrm{C}$ implying greater thermal stability of NDI-2 aggregates compared to NDI-1.

To ascertain the role of hydrogen-bonding in the self-assembly process, we further studied the effect of $\mathrm{MeOH}$, a protic solvent which is known to interfere with the hydrogen-bond formation on the spectral 

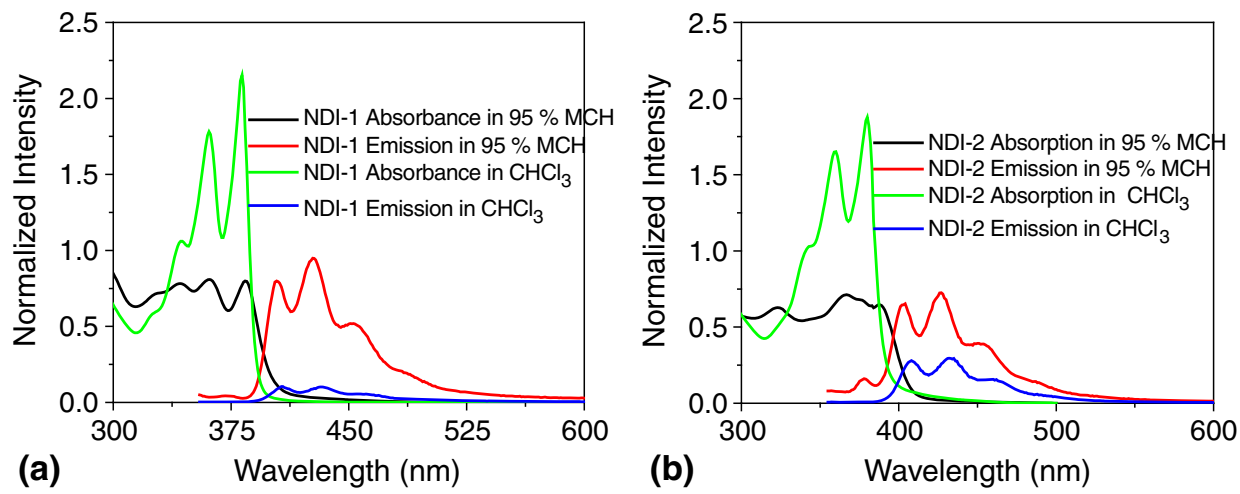

Figure 2. Solvent-dependent absorption and emission spectra $\left(\lambda_{\mathrm{ex}}=340 \mathrm{~nm}\right)$ of (a) NDI-1 and (b) NDI-2 in $\mathrm{CHCl}_{3}$ and $95: 5 \mathrm{MCH} / \mathrm{CHCl}_{3}$. Concentration $=0.1 \mathrm{mM}$, temperature $=25^{\circ} \mathrm{C}$. During normalization, the intensities of the most prominent peaks for absorption and emission in $95 \% \mathrm{MCH}$ were matched. The ratio of absorption and emission intensities in $\mathrm{CHCl}_{3}$ and $95 \% \mathrm{MCH}$ remains unaltered.

properties of the individual chromophores. With subsequent addition of $\mathrm{MeOH}$ to a solution of NDI-1 and NDI-2 in $95: 5 \mathrm{MCH} / \mathrm{CHCl}_{3}$, the spectral intensity increased drastically for both the chromophores (figure 4). For NDI-1 at $4.3 \% \mathrm{MeOH}$, the spectrum resembled that of the monomer with well-resolved absorption bands illustrating reversible disassembly with $\mathrm{MeOH}$ addition. Contrarily for NDI-2, in the presence of same amount of $\mathrm{MeOH}$ spectral pattern indicated presence of mostly aggregated chromophore. These observation clearly suggest that the self-assembled structure of NDI-2 is less sensitive to $\mathrm{MeOH}$ perturbation or in other words self-assembly of NDI-2 is stronger.

From the foregone description of experimental data it is evident that while the onset of aggregation happens at lower $\mathrm{MCH} / \mathrm{CHCl}_{3}$ composition for NDI-1, the variable-temperature as well as $\mathrm{MeOH}$ experiments suggest stronger self-assembly for NDI-2. To understand this apparent anomaly we propose the following argument. Self-assembly of both the chromophores are primarily driven by hydrogen-bonding among the amide groups while $\pi$-stacking is more of a consequence than a cause. But in the UV/Vis spectra we can only monitor signature of $\pi$-stacking but not hydrogenbonding directly. Greater propensity for the selfassembly of NDI-1 could be attributed to the symmetrical placement of the two amide groups along both arms of NDI-chromophore. In such molecular design, intermolecular hydrogen-bonding involving both the amide groups will also ensure $\pi$-stacking in tandem with the centrally located NDI-chromophores. Therefore the signature of $\pi$-stacking could be observed even at lower $\mathrm{MCH} / \mathrm{CHCl}_{3}$ ratio. Unlike NDI-1, molecular design of NDI-2 does not ensure $\pi$-stacking in concomitant with intermolecular hydrogen-bonding through the two amide groups because they are appended along same arm of NDI-chromophore. In this case, one cannot eliminate completely the possibility of various other modes of assembly where hydrogen-bonding does not necessarily ensure $\pi$-stacking (see Supporting Information,
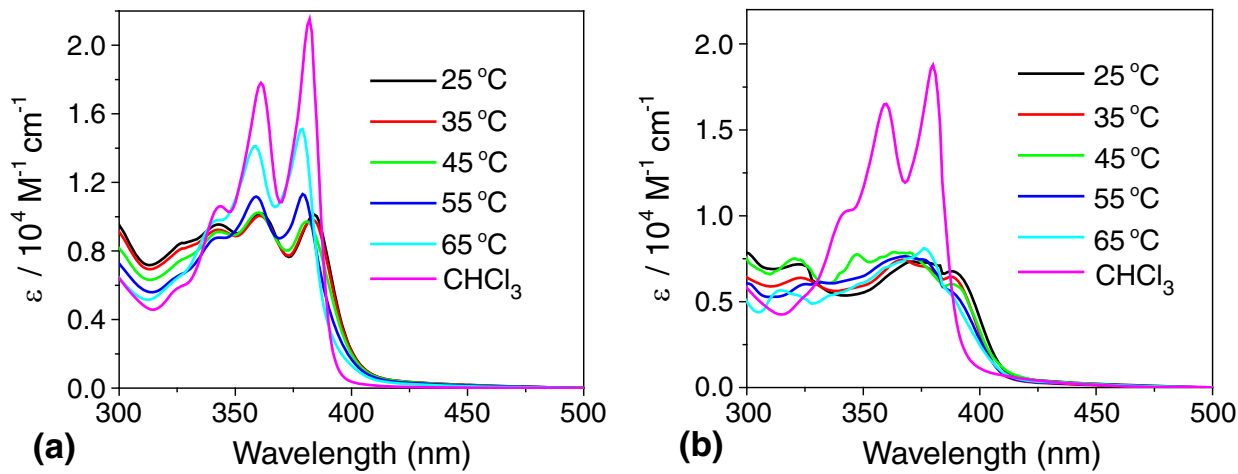

Figure 3. Temperature-dependent UV/Vis absorption spectra of (a) NDI-1 and (b) NDI-2 in 95:5 MCH/ $\mathrm{CHCl}_{3}$. Concentration $=0.1 \mathrm{mM}$. 

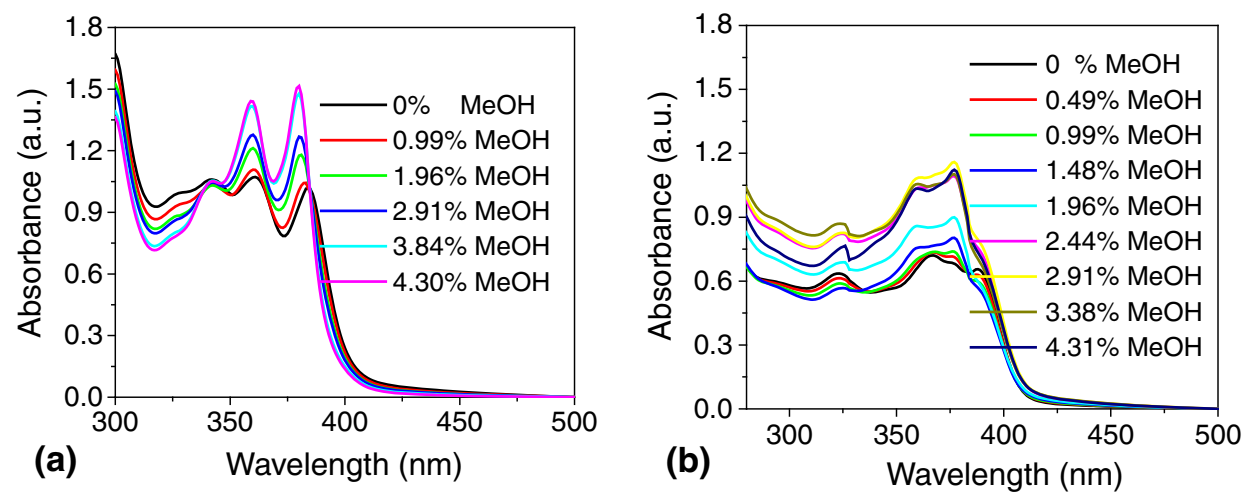

Figure 4. Effect of addition of $\mathrm{MeOH}$ on the absorption spectra of the self-assembled structure of (a) NDI-1 and (b) NDI-2 in 95:5 $\mathrm{MCH} / \mathrm{CHCl}_{3}$. Concentration $=0.1 \mathrm{mM}$, temperature $=25^{\circ} \mathrm{C}$.

figure S1). Thus the signature of $\pi$-stacking is observed at the later stage in solvent-variable UV/Vis spectroscopy. However, at very high $\mathrm{MCH}$ content $(95 \%)$ where $\pi$-stacked assembly is achieved for both the systems, NDI-2 becomes more stable because in this case the two amides are located in close proximity and this can impart stronger synergistic effect compared to that in NDI-1. So in terms of thermal stability, NDI-2 becomes superior self-assembled material.

\subsection{Gelation studies}

Contrasting difference in the self-assembly behaviour of the two isomers in solution phase prompted us to study their gelation ability at higher concentration in various non-polar organic solvents. Both NDI-1 and NDI-2 gelate various aliphatic (methylcyclohexane, cyclohexane) and chlorinated non-polar (TCE and $\mathrm{CCl}_{4}$ ) solvents. Unlike NDI-1, NDI-2 can also gelate aromatic solvent like toluene. However, we examined the gelation in $\mathrm{MCH}$ in detail for both the gelators and attempted to correlate it with solution self-assembly as described before. Both NDI-1 and NDI-2 formed spontaneous transparent gels in $\mathrm{MCH}$ with CGC of $0.9 \mathrm{mM}$ and $1.23 \mathrm{mM}$ respectively. Nature of the UV-Vis absorption spectra of both NDI-1 and NDI-2 in gel-state were found to be almost identical (figure S3) to those found for individual self-assembled solution in $\mathrm{MCH} / \mathrm{CHCl}_{3}$ (95:5). This suggests similar chromophore packing in gel and solution self-assembled state.

The thermal stability of the two gels were compared by measuring their sol-to-gel $\left(T_{\text {gel }}\right)$ transition temperature. At a particular concentration $(5 \mathrm{mM}), T_{\text {gel }}$ was found to be $84^{\circ} \mathrm{C}$ and $67^{\circ} \mathrm{C}$ for NDI-1 and NDI-2, respectively. We further studied the flow behaviour of the two gels by comparing their rheological properties in a stress-amplitude sweep measurement by monitoring the variation of $\mathrm{G}^{\prime}$ (storage modulus) and $\mathrm{G}^{\prime \prime}$ (loss modulus) as a function of applied stress (figure 5). For both isomers, the initial $G^{\prime}$ value was almost one order of magnitude higher than $\mathrm{G}^{\prime \prime}$ suggesting existence of gel phase. ${ }^{27}$ With increasing applied stress, $G^{\prime}$ and $G^{\prime \prime}$ remained invariant till a certain point beyond which they crossed each other. The crossing point is called yield stress which is a measure of the rigidity of the gel beyond which it begins to flow. From the plot, the yield stress for NDI-1 and NDI-2 were estimated to be 3.4 $\mathrm{Pa}$ and $1.2 \mathrm{~Pa}$, respectively. Thus the rheology data corroborates well with the $T_{\text {gel }}$ and CGC values to suggest symmetrically substituted NDI-1 as the better gelator compared to NDI-2. It can be recalled that in solvent dependent UV/Vis experiments we observed

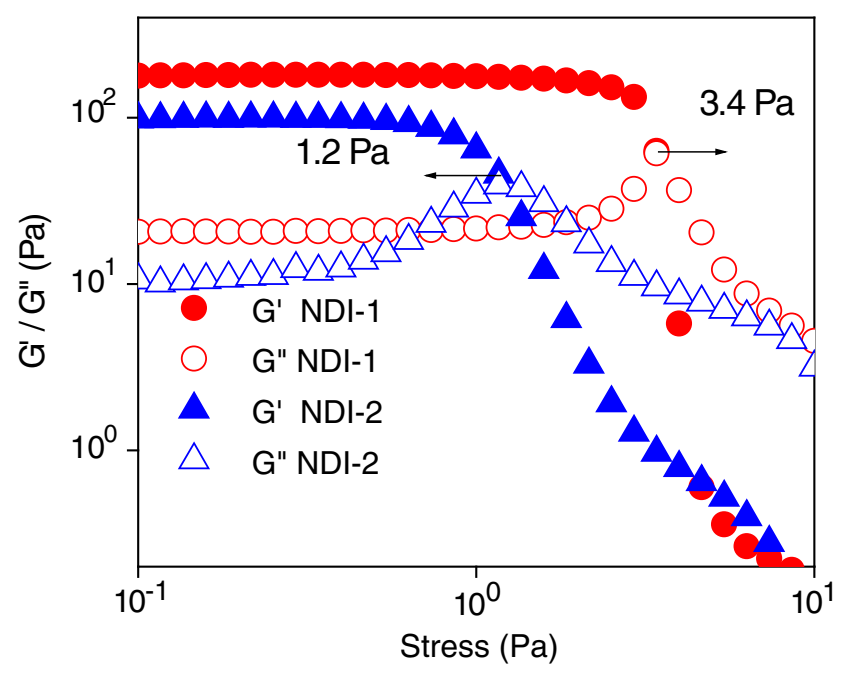

Figure 5. Variation of elastic modulus $\left(\mathrm{G}^{\prime}\right)$ and loss modulus $\left(\mathrm{G}^{\prime \prime}\right)$ as a function of applied stress for two gelators (solvent $-\mathrm{MCH}$, concentration $=0.7 \mathrm{wt} \%)$, temperature $=$ $25^{\circ} \mathrm{C}$. 


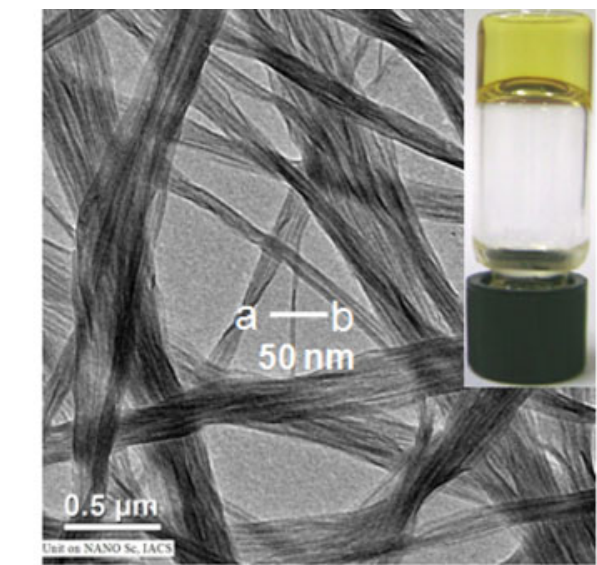

(a)

(b)

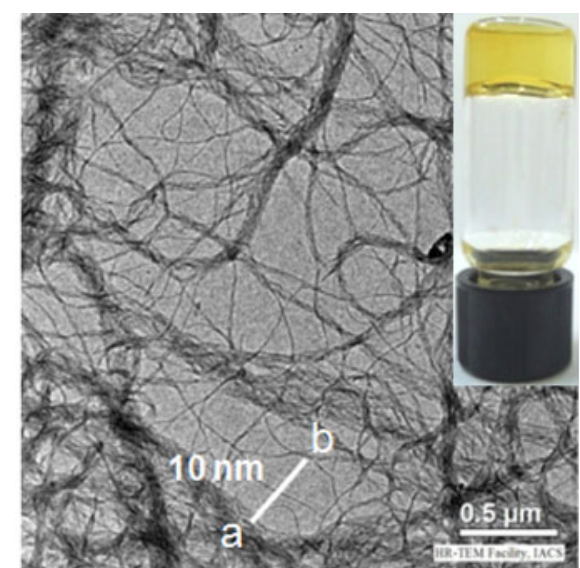

Figure 6. TEM images of (a) NDI-1 and (b) NDI-2 in 95:5 $\mathrm{MCH} / \mathrm{CHCl}_{3}$, concentration = $0.2 \mathrm{mM}$. Average diameter of the fibres are $50 \mathrm{~nm}$ and $10 \mathrm{~nm}$ for NDI-1 and NDI-2 respectively. Inset shows the gel pictures $(\mathrm{C}=10 \mathrm{mM})$.

onset of $\pi$-stacking at much lower MCH content which indicated more coherent relationship between hydrogen-bonding and $\pi$-stacking for NDI-1. On the other hand, for NDI-2 even though higher thermal stability was observed, we predicted in this case there may be more poorly-defined aggregation as hydrogenbonding and $\pi$-stacking not necessarily have to operate together due to structural flexibility.

It is interesting to note that such effect in selfassembly is clearly reflected in their gelation property. Furthermore, the morphology of the self-assembled structures were examined by TEM-studies which also revealed organized, regular, entangled bundles of nanorods for NDI-1 (figure 6a). In contrast, the gel fibres obtained from NDI-2 (figure $6 \mathrm{~b}$ ) were relatively thin and less ordered which could be attributed by possibilities of more than one type of aggregation of NDI-2 chromophores in solution as described before. It is noteworthy that the present study is another example that stronger self-assembly alone is not adequate to ensure better gelation. Previously we have reported flexibility of the self-assembled fibres and their morphology play critical role to define a good gelator. ${ }^{28}$ Here we showed 'purity' of the nature of the assembled structure is also important for good gelation property. In this context it can be recalled that although the thermal stability of self-assembled NDI-2 > NDI-1 (figure 3), aggregationinduced emission enhancement was more prominent for NDI-1 (figure 2) further indicating more defined chromophore-packing in the self-assembled state.

Having studied gelation of two chromophores in solution now we were also curious to examine correlating solvent effect in self-assembly and gelation for one of the chromophores (NDI-2). For that, we checked the gelation ability of NDI-2 in TCE and observed spontaneous gelation with CGC $(1.0 \mathrm{mM})$ as in $\mathrm{MCH}$. However, in TCE, $T_{\text {gel }}$ was measured to be $53^{\circ} \mathrm{C}$ which is significantly lower compared to that in $\mathrm{MCH}\left(67^{\circ} \mathrm{C}\right)$. To examine whether relatively poor gelation properties of NDI-2 in TCE compared to those in MCH can be correlated with solution self-assembly we checked the variable-temperature UV/Vis spectra of NDI-2 in TCE (figure 7).

Compared to $\mathrm{CHCl}_{3}$, clear spectral changes were observed in TCE indicating $\pi$-stacking. With increasing temperature in this case, signature of disassembly was observed beyond $45^{\circ} \mathrm{C}$. While in 95:5 $\mathrm{MCH} / \mathrm{CHCl}_{3}$, even at $65^{\circ} \mathrm{C}$, almost no spectral changes were noticed (figure $3 \mathrm{~b}$ ). This clearly indicates higher thermal stability of

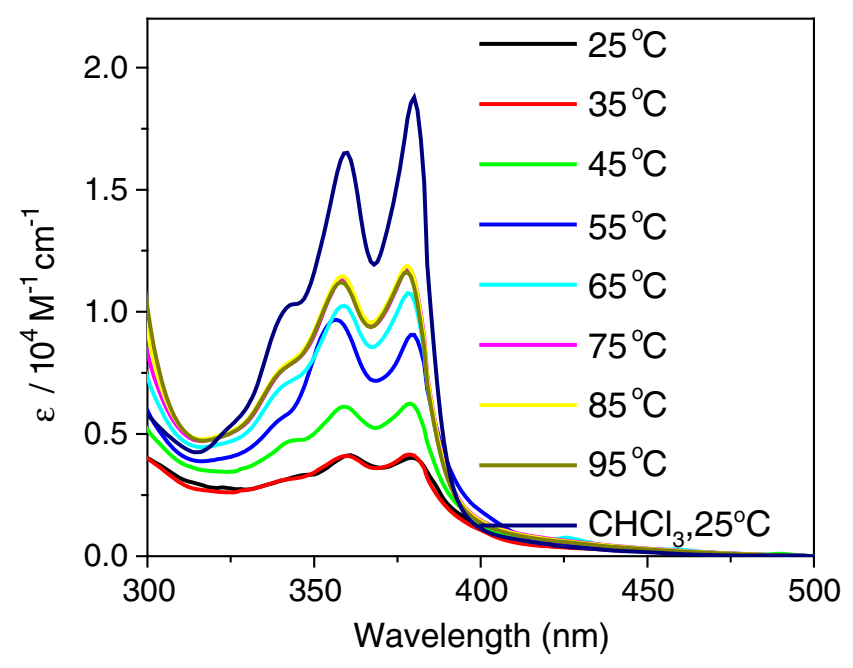

Figure 7. Temperature-variable UV/Vis absorption spectra of NDI-2 in TCE. Concentration $=0.1 \mathrm{mM}$. 


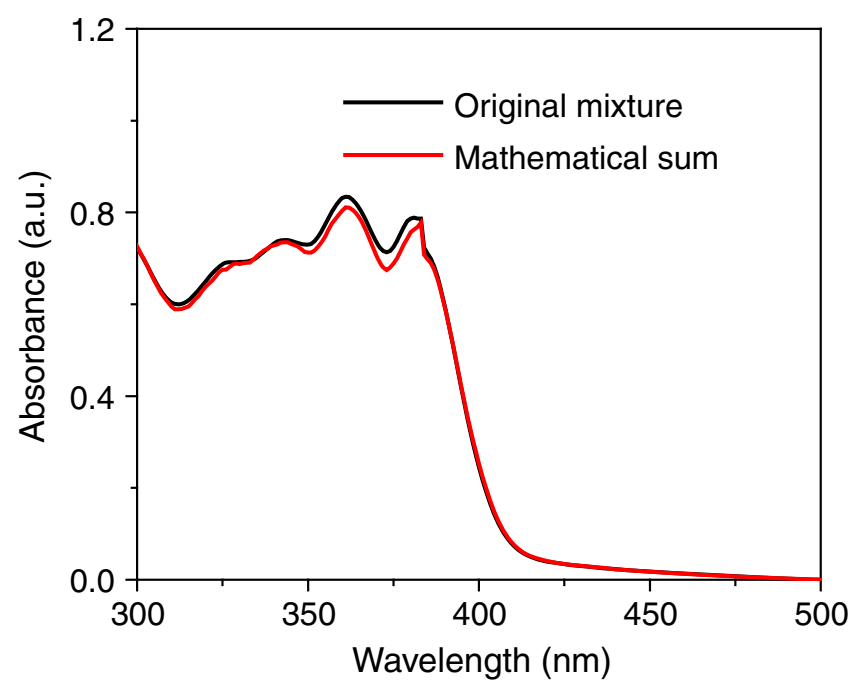

Figure 8. UV/Vis spectrum of NDI-1 + NDI-2 (1:1) in 95:5 $\mathrm{MCH} / \mathrm{CHCl}_{3}$ and the mathematical sum of the individual spectra (concentration $=0.1 \mathrm{mM})$.

self-assembly in MCH compared to TCE which corroborates well with the comparative gelation data.

\subsection{Self-sorting}

Having studied the individual self-assembly we further probed the behaviour in the mixture of the two chromophores. As the distance among the two amide groups are very different for NDI-1 and NDI-2, we envisaged in their mixture two chromophores should maintain their identity in terms of self-assembly to maximize the hydrogen-bonding and thus should undergo orthogonal self-assembly to generate self-sorted systems. ${ }^{29,30}$ To test this hypothesis, we have examined the spectral behaviour of NDI-1 + NDI-2 (1:1) in 95:5 MCH$/ \mathrm{CHCl}_{3}$ and compared it with the mathematical summation of the aggregated spectra of the individual chromophores (figure 8). It was observed that the spectra for the original mixture and the mathematical summation of NDI-1 and NDI-2 are almost identical suggesting no molecular interaction between the two gelators.

Orthogonal self-assembly was also probed by ${ }^{1} \mathrm{H}$ NMR experiment. Firstly, ${ }^{1} \mathrm{H}$ NMR spectra of the two chromophores were taken in $\mathrm{CDCl}_{3}$ at room temperature

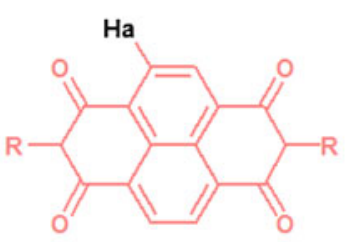

NDI-1

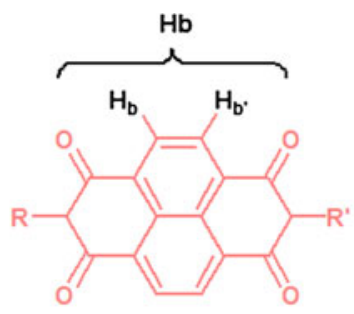

$\mathrm{NDI}-2$

$\mathrm{NDI}-1\left(\mathrm{TCE}, 60^{\circ} \mathrm{C}\right)$

$\mathrm{NDI}-1+\mathrm{NDI}-2\left(\mathrm{TCE}, 60^{\circ} \mathrm{C}\right)$

$\mathrm{NDI}-2\left(\mathrm{TCE}, 60^{\circ} \mathrm{C}\right)$

$\mathrm{NDI}-1+\mathrm{NDI}-2\left(\mathrm{TCE}, 40^{\circ} \mathrm{C}\right)$

NDI-2 (TCE, $\left.40^{\circ} \mathrm{C}\right)$

$\mathrm{NDI}-1\left(\mathrm{TCE}, 40^{\circ} \mathrm{C}\right)$

$\mathrm{NDI}-2\left(\mathrm{CDCl}_{3}\right)$

$\mathrm{NDI}-1\left(\mathrm{CDCl}_{3}\right)$

\begin{tabular}{|c|c|c|c|}
\hline & & 1 & \\
\hline $\mathrm{ppm}(\mathrm{t} 1)$ & 8.50 & 8.00 & 7.50 \\
\hline
\end{tabular}

Figure 9. Solvent- and temperature-dependent proton NMR spectra (selected region) of NDI-1 and NDI-2 gels. In case of TCE, $10 \% \mathrm{C}_{6} \mathrm{D}_{6}$ was added for locking the signal. Individual concentration $=2.5 \mathrm{mM}$. 


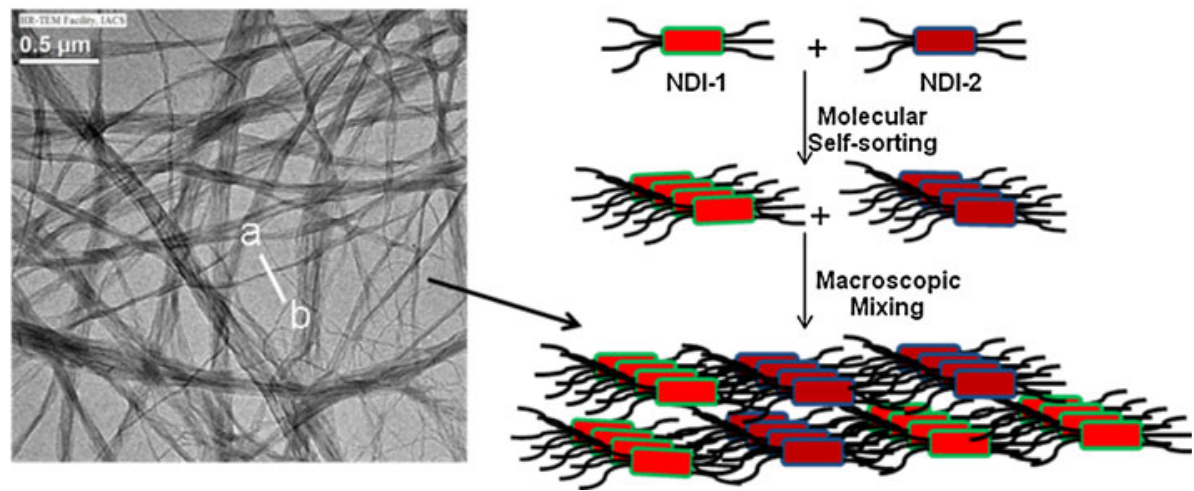

Figure 10. Left: TEM images of (NDI-1 + NDI-2) in 95:5 $\mathrm{MCH} / \mathrm{CHCl}_{3}$, total concentration $=0.2 \mathrm{mM}$. Diameter of the fibre shown $(\mathrm{a}-\mathrm{b})=30 \mathrm{~nm}$; Right: Schematic presentation of proposed macroscopic mixing of molecularly self-sorted gel fibrils.

in which they remain in their monomeric form. Figure 9 shows the part of the NMR spectra where sharp aromatic proton signals for the NDI-chromophore is observed in both case with chemical shift values of $8.61 \mathrm{ppm}$ and $8.59 \mathrm{ppm}$ for NDI-1 and NDI-2, respectively. Owing to very strong assembly in $\mathrm{MCH}$ the signals became so broad that they could not be observed at $40^{\circ} \mathrm{C}$. To overcome this problem we conducted the NMR experiments in TCE in which the self-assembly was found to be inherently weaker than $\mathrm{MCH}$.

At $40^{\circ} \mathrm{C}$ in TCE, Ha signal could be observed at $8.42 \mathrm{ppm}$, which is significantly upfield shifted compared to $\mathrm{CDCl}_{3}$ suggesting self-assembly in TCE while $\mathrm{Hb}$ signal could not be observed further supporting stronger self-assembly for NDI-2. Now we monitored the NMR spectra for the mixture NDI-1 + NDI-2 (1:1) in TCE, at $40^{\circ} \mathrm{C}$ where only one proton signal $(8.40 \mathrm{ppm})$ was observed in the NDI-region which almost matched with that of NDI-1 (8.42 ppm) alone at $40^{\circ} \mathrm{C}$ suggesting that the mode of assembly of NDI-1 in the mixture is identical to NDI-1 alone in TCE. To monitor the peak corresponding to $\mathrm{Hb}$ protons the NMR experiment was performed at $60^{\circ} \mathrm{C}$ hoping that at this temperature selfassembly of NDI-2 chromophores will become relatively weaker and will make $\mathrm{Hb}$ proton signal visible. It was indeed the case and the signal corresponding to $\mathrm{Hb}$ protons could be now observed for both the individual $(8.45 \mathrm{ppm})$ and the mixed gel $(8.43 \mathrm{ppm})$. It is interesting to note that signal for $\mathrm{Ha}$ and $\mathrm{Hb}$ protons was found to be almost matching in the individual gels and the mixture at $60^{\circ} \mathrm{C}$ confirming self-sorted assembly of NDI-1 and NDI-2 in their equimolar mixture.

Further, we attempted to examine the morphology of mixed assembly of NDI-1 + NDI-2 (1:1) in gel state. TEM images of the mixed gel (figure 10) revealed micrometer long inter-linked fibres typical of a gel phase. Unlike spectroscopic measurements, in this case identity of the individual gel fibres could not be traced in the TEM images of the mixed gel. It is important to realize that individual gelators first forms selfassembled fibrils which further assembled together to generate the fibres (figure 10, right) that we observe in the TEM images.

The supramolecular design for self-sorting is no longer valid in the macroscopic mixing of individual fibrils because both types of fibrils are encased with similar hydrophobic peripheral alkyl chain. In macroscopic level mixing of two types of fibrils happen indiscriminately. Thus in the mixed gel we could not identify two types of fibres for individual gelators. Note that we have recently demonstrated such macroscopic mixing of molecularly self-sorted donor and acceptor fibrils by extensive circular dichroism studies. ${ }^{31}$

\section{Conclusion}

In summary, we have reported the contrasting effect of variation in location of two amide groups on hydrogenbonding mediated self-assembly and gelation of two isomeric NDI-derivatives. In both cases self-assembly was observed in $\mathrm{MCH}$ due to cooperative effect of $\pi$ stacking and hydrogen-bonding but the propensity for self-assembly of NDI-1 was found to be greater owing to the symmetric placement of the two amide groups on either arms of NDI-chromophore which allowed $\pi$-stacking concomitantly with hydrogen-bonding with the neighbouring groups. Surprisingly, NDI-2 showed thermally more stable self-assembled fibres possibly due to stronger hydrogen-bonding which could be ascribed to the placement of two amide groups in close proximity on single arm of this chromophore. Further, 
we examined the gelation of the two isomeric chromophores which helped us to understand the relationship between the nature of self-assembly and morphology of the self-assembled fibres to the macroscopic gelation property. We also probed self-assembly in the mixed system which revealed self-sorting among the two building blocks which is a recent topic of interest among various functional chromophores. Currently we are exploring the possibilities of utilizing the directional self-assembly in asymmetric gelator such as NDI-2 to achieve supramolecular anchoring of various functional moieties to generate composite materials for organic electronic applications.

\section{Supporting information}

Figures S1-S3 given as supporting material can be seen in www.ias.ac.in/chemsci Website.

\section{Acknowledgements}

We thank the Department of Science and Technology (DST), New Delhi, India, for financial support (Project SR/FT/CS-039/2008). AD and MRM thank Council of Scientific and Industrial Research (CSIR) and Indian Association for the Cultivation of Science (IACS), respectively, for a research fellowship.

\section{References}

1. (a) Lehn J-M 1995 Supramolecular chemistry-concepts and perspectives (Weinheim, Germany: Wiley-VCH); (b) 2005 Supramolecular dye chemistry, topics in current chemistry F Würthner (ed.) (Berlin, Germany: Springer) 258; (c) Palmer L C and Stupp S I 2008 Acc. Chem. Res. 41 1674; (d) Souza F and Ito O 2009 Chem. Commun. 4913; (e) Malinovskii V L, Wenger D and Häner R 2010 Chem. Soc. Rev. 39 410; (f) Hoeben F J M, Jonkheijm P, Meijer E W and Schenning A P H J 2005 Chem. Rev. 1051491

2. (a) Melendez R E, Carr A J, Linton B R and Hamilton A D 2000 Struct. Bonding (Berlin) 96 31; (b) Laurent H B and Desvergne J P 2006 Molecular gels: Materials with self-assembled fibrillar networks R G Weiss, P Terech (eds.) (Dordrecht, The Netherlands: Springer) Chapter 12; (c) 2005 Low molecular mass gelators, topics in current chemistry F Fages (ed.) (Berlin, Germany: Springer) 256; (d) Beginn U 2003 Prog. Polym. Sci. 28 1049; (e) Banerjee S, Das R K and Maitra U 2009 J. Mater. Chem. 19 6649; (f) Suzuki M and Hanabusa K 2010 Chem. Soc. Rev. 39 455; (f) Bhattacharya S and Samanta S K 2009 Langmuir 258378

3. (a) Hains A W, Liang Z, Woodhouse M A and Gregg B A 2010 Chem. Rev. 1106689 and references therein; (b) Ajayaghosh A, Praveen V K and Vijayakumar C 2008 Chem. Soc. Rev. 37109
4. (a) Tamaru S I, Nakamura M, Takeuchi M and Shinkai S 2001 Org. Lett. 3 3631; (b) Shirakawa M, Kawano S I, Fujita N, Sada K and Shinkai S 2003 J. Org. Chem. 68 5037

5. (a) Mishra A, Ma C-Q and Bauerle P 2009 Chem. Rev. 109 1141; (b) Prasanthkumar S, Saeki A, Seki S and Ajayaghosh A $2010 \mathrm{~J}$. Am. Chem. Soc. 132 8866; (c) Prasanthkumar S, Gopal A and Ajayaghosh A 2010 J. Am. Chem. Soc. 132 13206; (d) Schoonbeek F S, Van Esch J H, Wegewijs B, Rep D B A, De Haas M P, Klapwijk T M, Kellogg R M and Feringa B L 1999 Angew. Chem. Int. Ed. 38 1393; (e) Kawano S, Fujita N and Shinkai S 2005 Chem. Eur. J. 11 4735; (f) Stone D A, Tayi A S, Goldberger J E, Palmer L C and Stupp S I 2011 Chem. Commun. 5702; (g) Pratihar P, Ghosh S, Stepanenko V, Patwardhan S, Grozema F C, Siebbeles L D A and Würthner F 2010 Beilstein J. Org. Chem. 61070

6. Engelkamp H, Middelbeek S and Nolte R J M 1999 Science $\mathbf{2 8 4} 785$

7. (a) Ajayaghosh A and Praveen V K 2007 Acc. Chem. Res. 40644 and references therein; (b) Babu S S, Kartha K K and Ajayaghosh A 2010 J. Phys. Chem. Lett. 1 3413; (c) Srinivasan S, Babu P A, Mahesh S and Ajayaghosh A 2009 J. Am. Chem. Soc. 131 15122; (d) Vijayakumar C, Praveen V K, Kartha K K and Ajayaghosh A 2011 Phys. Chem. Chem. Phys. 13 4942; (e) Samanta S K, Pal A and Bhattacharya S 2009 Langmuir 25 8567; (f) Goel M and Jayakannan M $2010 \mathrm{~J}$. Phys. Chem. 11412508

8. (a) Puigmartì-Luis J, Pino À P, Laukhin V, Feldborg L N, Rovira C, Laukhina E and Amabilino D B 2010 J. Mater. Chem. 20 466; (b) Puigmartì-Luis J, Laukhin V, Pino À P, V-Gancedo J, Rovira C, Laukhina E and Amabilino D B 2007 Angew. Chem. Int. Ed. 46 238; (c) Akutagawa T, Kakiuchi K, Hasegawa T, Noro S-i, Nakamura T Hasegawa H, Mashiko S, Becher J 2005 Angew. Chem. Int. Ed. 447283

9. (a) Würthner F 2004 Chem. Commun. 1564; (b) Sugiyasu K, Fujita N and Shinkai S 2004 Angew. Chem. Int. Ed. 43 1229; (c) Li X-Q, Stepanenko V, Chen Z, Prins P, Siebbeles L D A and Würthner F 2006 Chem. Commun. 3871; (d) Würthner F, Bauer C, Stepanenko V and Yagai S 2008 Adv. Mater. 20 1695; (e) Wicklein A, Ghosh S, Sommer M, Würthner F and Thelakkat M 2009 ACS Nano 3 1107; (f) Sugiyasu K, Kawano S-i, Fujita N and Shinkai S 2008 Chem. Mater. 202863

10. Mukhopadhyay P, Iwashita Y, Shirakawa M, Kawano S-i, Fujita N and Shinkai S 2006 Angew. Chem. Int. Ed. 451592

11. (a) Würthner F, Yao S and Beginn U 2003 Angew. Chem. Int. Ed. 42 3247; (b) Yagai S, Ishii M, Karatsu T and Kitamura A 2007 Angew. Chem. Int. Ed. 468005

12. Molla M R and Ghosh S 2011 Chem. Mater. 2395

13. (a) Miller L L, Mann K R 1996 Acc. Chem. Res. 29 417; (b) Katz H E, Lovinger A J, Johnson J, Kloc C, Siegrist T, Li W, Lin Y Y and Dodabalapur A 2000 Nature 404 478; (c) Warman J M, de Haas M P, Dicker G, Grozema F C, Piris J and Debije M G 2004 Chem. Mater. 16 4600; (d) Jones B A, Facchetti A, Wasielewski M R and Marks T J 2007 J. Am. Chem. Soc. 129 15259; (e) Oh B J H, 
Suraru S L, Lee W Y, Könemann M, Höffken H W, Röger C, Schmidt R, Chung Y, Chen W C, Würthner F and Bao Z 2010 Adv. Funct. Mater. 202148

14. (a) Lokey R S and Iverson 1995 B L Nature 375 303; (b) Nguyen J Q and Iverson B L 1999 J. Am. Chem. Soc. 121 2639; (c) Zych A J and Iverson B L $2000 \mathrm{~J}$. Am. Chem. Soc. 122 8898; (d) Gabriel G J and Iverson B L 2002 J. Am. Chem. Soc. 124 15174; (e) Cubberley M S and Iverson B L $2001 \mathrm{~J}$. Am. Chem. Soc. 123 7560; (f) De S and Ramakrishnan S 2011 Chem. Asian J. 6149

15. (a) Vignon $\mathrm{S} A$, Jarrosson $\mathrm{T}$, Iijima $\mathrm{T}$, Tseng $\mathrm{H}-\mathrm{R}$, Sanders J K M and Stoddart J F 2004 J. Am. Chem. Soc. 126 9884; (b) Iijima T, Vignon S A, Tseng H R, Jarrosson T, Sanders J K M, Marchioni F, Venturi M, Apostoli E, Balzani E and Stoddart J F 2004 Chem. Eur. J. 10 6375; (c) Mullen K M, Davis J J and Beer P D 2009 New. J. Chem. 33769

16. (a) Au-Yeung H Y, Pantos G D and Sanders J K M 2010 Angew. Chem. Int. Ed. 49 5331; (b) Au-Yeung H Y, Pantos G D and Sanders J K M 2009 Proc. Natl. Acad. Sci. U.S.A. 106 10466; (c) Au-Yeung H Y, Pantos G D and Sanders J K M 2009 J. Am. Chem. Soc. 131 16030; (d) Coskun A, Saha S, Aprahamian I and Stoddart J F 2008 Org. Lett. 103187

17. (a) Talukdar P, Bollot G, Marenda J, Sakai N and Matile S J 2005 Am. Chem. Soc. 127 6528; (b) Hagihara S, Gremaud L, Bollot G, Mareda J and Matile S 2008 J. Am. Chem. Soc. 1304347

18. Kumar M and George S J 2011 Nanoscale 32130

19. (a) Bhosale R, Míšek J, Sakai N and Matile S 2010 Chem. Soc. Rev. 39 138; (b) Röger C, Mueller M G, Lysetska M, Miloslavina Y, Holzwarth A R and Würthner F 2006 J. Am. Chem. Soc. 128 6542; (c) Röger C, Miloslavina Y, Brunner D, Holzwarth A R and Würthner F 2008 J. Am. Chem. Soc. 130 5929; (d) Sakai N, Sisson A L, Bürgi T and Matile S 2007 J. Am. Chem. Soc. 129 15758; (e) Sakai N, Bhosale R, Emery D, Mareda J and Matile S $2010 \mathrm{~J}$. Am. Chem. Soc. 132 6923; (f) Bhosale S, Sisson A L, Talukdar P, Fürstenberg A, Banerji N, Vauthey E, Bollot G, Mareda J, Röger C, Würthner F, Sakai N and Matile S 2006 Science 31384

20. Molla M R, Das A and Ghosh S 2010 Chem. Eur. J. 16 10084

21. Das A and Ghosh S 2011 Chem. Commun. 8922

22. (a) Note that in this case no separate absorption peak for aggregates are observed, rather the whole spectrum undergoes hypochromic shift along with concomitant red-shift which results in tailing of the lowest energy absorption band till $\sim 410 \mathrm{~nm}$. It is noteworthy that beyond $80 \% \mathrm{MCH} / \mathrm{CHCl}_{3}$ although the absorption intensity at $382 \mathrm{~nm}$ continues to decrease (at slower rate) with increasing $\mathrm{MCH}$ content, the intensity of the tail at $390 \mathrm{~nm}$ does not change any further. This is probably because at this stage the increase in absorption at $390 \mathrm{~nm}$ due to red shift is coincidently cancelled out by the hypochromic effect of the whole spectrum. (b) Shao H, Nguyen T, Romano N C, Modarelli D A and Parquette J R 2009 J. Am. Chem. Soc. 13116374

23. Ghosh S, Li X-Q, Stepanenko V and Würthner F 2008 Chem. Eur. J. 1411343

24. (a) Shao H and Parquette J R 2010 Chem. Commun. 4285; (b) Tsai W W, Li L S, Cui H G, Jiang H Z and Stupp S I 2008 Tetrahedron 64 8504; (c) Kawano S, Fujita N and Shinkai S 2005 Chem. Eur. J. 11 4735; (d) Schenning A P H J, Kilbinger A F M, Biscarini F, Cavallini M, Cooper H J, Derrick P J, Feast W J, Lazzaroni R, Leclere N, Meijer E W and Meskers S C J 2002 J. Am. Chem. Soc. 1241269

25. Okazaki T, Iizumi Y, Okubo S, Kataura H, Liu Z, Suenaga K, Tahara Y, Yudasaka M, Okada S and Iijima S 2011 Angew. Chem. Int. Ed. 504853

26. (a) Würthner F, Hanke B, Lysetska M, Lambright G, and Harms G S 2005 Org. Lett. 7 967; (b) Rohr U, Schlichting P, Böhm A, Groû M, Meerholz K, Bräuchle C and Müllen K 1998 Angew. Chem. Int. Ed. 37 1434; (c) Dotcheva D, Klapper M and Müllen K 1994 Macromol. Chem. Phys. 195 1905; (d) Schneider M and Müllen K 2000 Chem. Mater. 12 352; (e) Gvishi R, Reisfeld R and Burshtein Z 1993 Chem. Phys. Lett. 213338

27. Raghavan S R and Cipriano B H 2006 Molecular gels: Materials with self-assembled fibrillar networks R G Weiss, P Terech (eds.) (Dordrecht, The Netherlands: Springer) Chapter 8

28. Das A and Ghosh S 2010 Chem. Eur. J. 1613622

29. For general references on self-sorting see: (a) Northrop H, Zheng Y-R, Chi Ki-Whan and Stang P J 2009 Acc. Chem. Res. 42 1554; (b) Pal A, Karthikeyan S and Sijbesma R P 2010 J. Am. Chem. Soc. 132 7842; (c) Mukhopadhyay P, Zavalij P Y and Isaacs L 2006 J. Am. Chem. Soc. 128 14093; (d) Heeres A, Pol C $\mathrm{v}$ d, Stuart M, Friggeri A, Feringa B L and Esch J v 2003 J. Am. Chem. Soc. 125 14252; (e) Moffat J R and Smith D K 2009 Chem. Commun. 316; (f) Rudzevich Y, Rudzevich V, Klautzsch F, Schalley C A and Bçhmer V 2009 Angew. Chem. Int. Ed. 48 3867; (g) Herrikhuyzen J van, Syamakumari A, Schenning A P H J and Meijer E W 2004 J. Am. Chem. Soc. 12610021

30. For self-sorting of Naphthalenediimide system see (a) ref 20; (b) ref 21; (c) Das A, Molla M R, Banerjee A, Paul A and Ghosh S 2011 Chem. Eur. J. 176061

31. Molla M, Das A and Ghosh S 2011 Chem. Commun. 8934 